\title{
Telescopic Hybrid Denture Prosthesis with Anterior Metal Ceramic Crowns
}

\author{
Sushmita VP ${ }^{1 *}$, Vinaya Bhat $^{2}$ and Chethan Hegde ${ }^{2}$ \\ ${ }^{1}$ Department of Prosthodontics, Sri Ramakrishna Dental College and Hospital, India \\ ${ }^{2}$ Department of Prosthodontics, AB Shetty Memorial Institute of Dental Sciences, India
}

*Corresponding author: Sushmita VP, Senior Lecturer, Department of Prosthodontics, Sri Ramakrishna Dental College and Hospital, Coimbatore, India

\section{Introduction}

While restoring patients with poor oral hygiene, it is mandatory to consider the self-cleansing ability of the prosthesis to reduce the risk of progression of the disease. The use of telescopic retainers continues to allow treatment options for prostheses that facilitate access for cleaning by the patient and/or dentist and retain questionable teeth longer. The concept of removable telescopic partial denture resulted from clinical experiments with the tooth supported complete denture [1]. It is also considered as a removable periodontal prosthesis, as it provides cross arch splinting of the periodontally compromised teeth and helps in equally distributing the forces along the long axis of the abutment [2-6]. In addition, a telescopic prosthesis can be designed to be cemented with light cement, which can satisfy a patient's need for a fixed prosthesis, but also allow for removal by a dentist to carryout prophylactic procedure to maintain hygiene. In this case report, a patient was successfully rehabilitated with a removable telescopic crown retained hybrid denture with metal ceramic crown on the remaining anterior teeth.

\section{Case Report}

Patient aged 45 years reported to the Department of Prosthodontics, AB Shetty Memorial Institute of Dental Sciences, Mangalore, with the chief complaint of multiple missing teeth and a desire to replace them. On examination there was loss of vertical dimension with collapse of occlusion. The remaining teeth 13 , 21, 22, 23, 31, 32, 33, 34, 35, 42 and 43 (Figure 1) were found to be periodontally compromised and with deep carious lesions. After periodontal and radiographic examination 21, 31, 32, 42 were found to have poor prognosis and it was decided to extract these teeth, other teeth were endodontically treated and used for retention of the prosthesis.
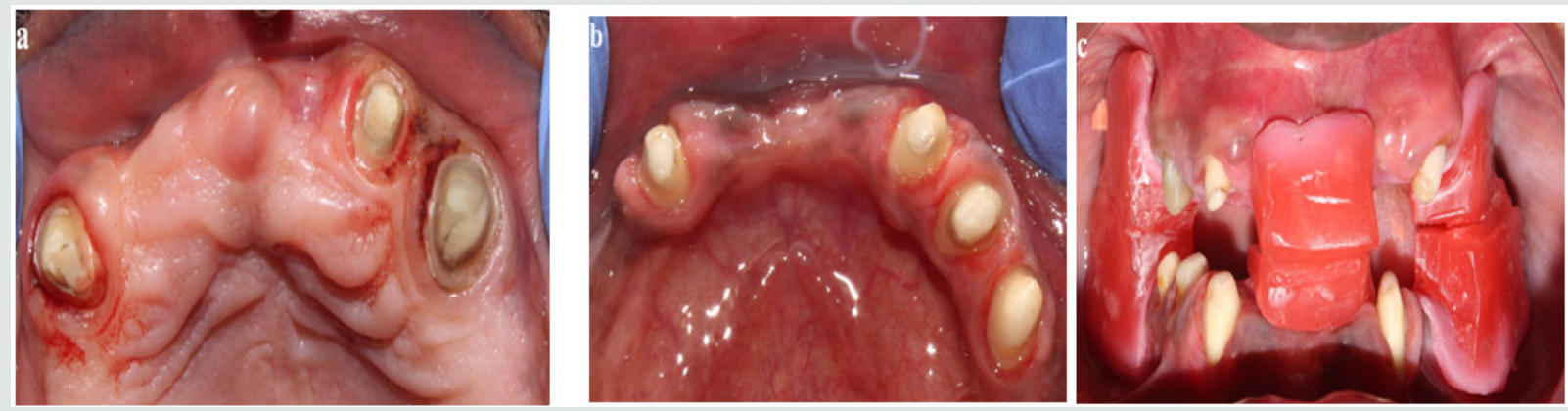

Figure 1: Tooth preparation was done and checked for adequate clearance.

Diagnostic impressions were made, and casts were fabricated. Tentative jaw relation was recorded and facebow transfer was done using artex rotofix facebow. The study casts were mounted in an arcon semi adjustable articulator. Mounted study casts were analyzed. Endodontic therapy was carried out for the remaining salvaged teeth. A telescopic hybrid prosthesis with porcelain fused to metal crown for the anterior teeth was planned to rehabilitate the patient. 


\section{Fabrication of primary coping}

a) A tentative jaw relation was recorded, and the casts were mounted. It was observed that the patient had class II jaw relation, with $7 \mathrm{~mm}$ of horizontal overlap of anterior teeth.

b) After endodontic treatment was completed, the teeth were prepared to receive the primary copings. Clearance was checked by using the tentative jaw relation record (Figure 2a2d). c) Wax patterns for primary coping were fabricated and surveyed to ensure parallelism. Casting was done using base metal alloy. Then the copings were trimmed and checked for the fit in the patient's mouth, following which a pickup impression was made (Figure 3) and casts were poured.

d) Final milling was done using two degree tapered milling bur and they were cemented using resin cement U200 from 3M (Figure 4).
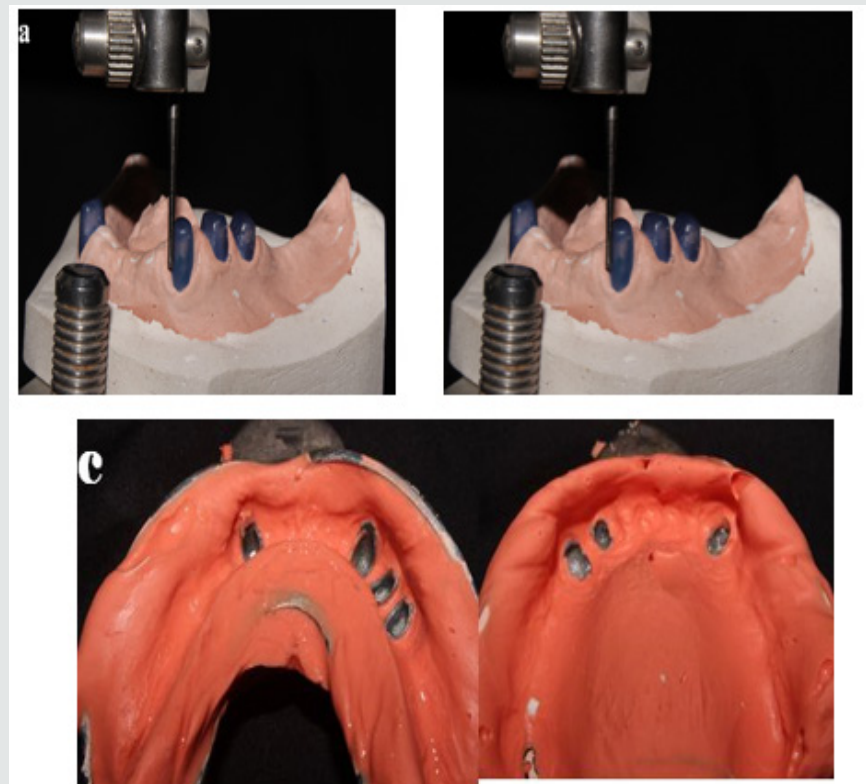

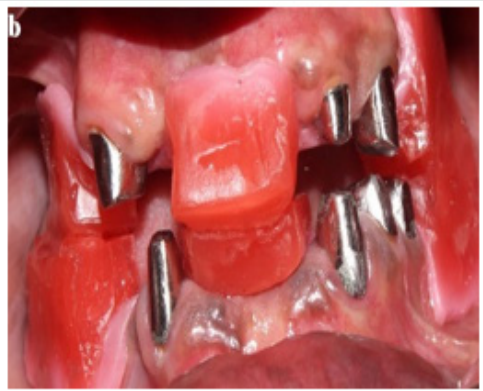

d

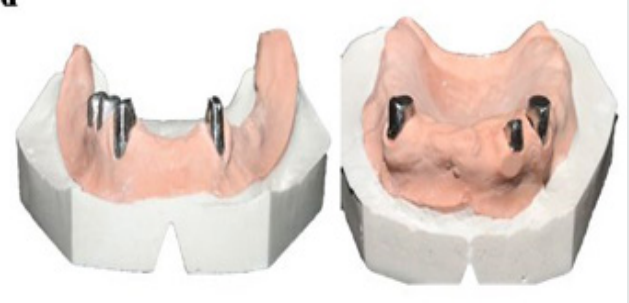

Figure 2: a) Surveying of primary copings; b) Tryin of primary coping; c) Pickup impression of the primary copings, d) Cast made from the pickup impression
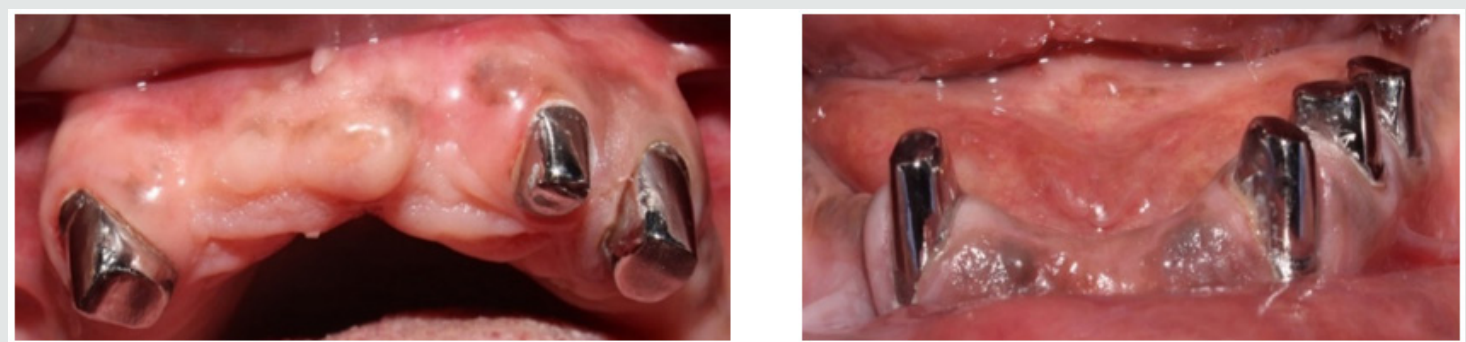

Figure 3: Cemented primary copings.

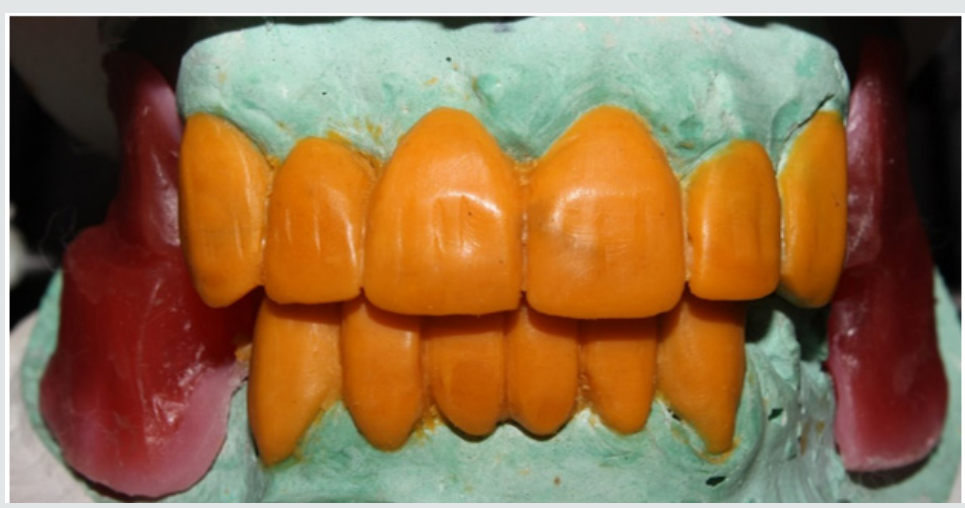

Figure 4: Wax mock-up. 


\section{Establishing anterior occlusal plane}

a) Anterior teeth were aesthetically modified, and missing teeth were fabricated with wax (Figure 5).

b) An index was made from this wax pattern using heavy body putty material. Later it was duplicated using tooth colored composite resin (protemp) to form a template. Template was trimmed, finished and polished. It was then tried in the mouth to determine the anterior plane of the maxillary teeth according to aesthetics and phonetics.

c) After establishing the plane of the maxillary anterior teeth, the position of the lower anterior was also decided in the similar manner based on phonetics, overjet and overbite (Figure 6). Anterior guidance was determined based on phonetics and aesthetics.
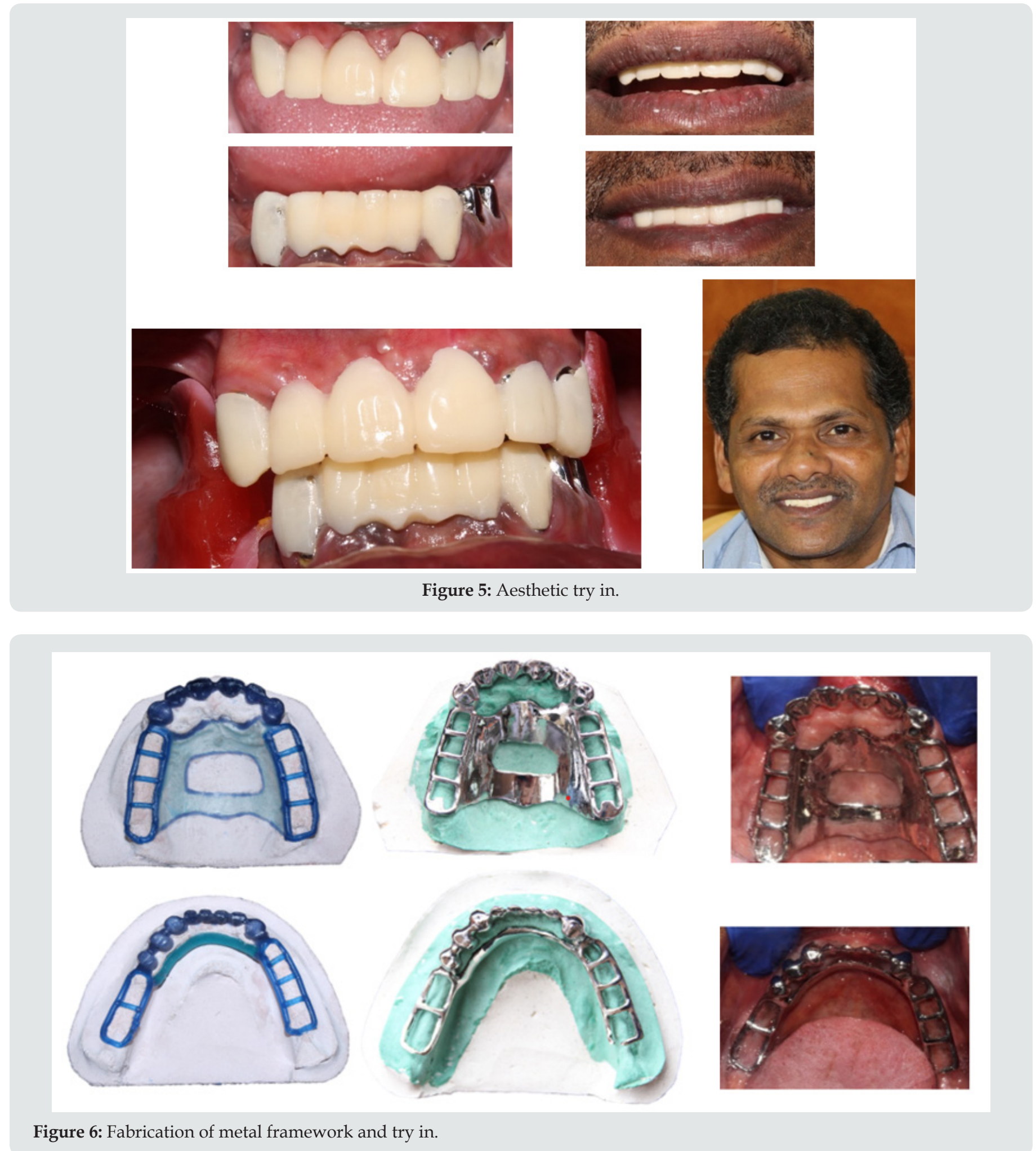

Citation: Sushmita VP, Vinaya B, Chethan H. Telescopic Hybrid Denture Prosthesis with Anterior Metal Ceramic Crowns. Mod App Dent Oral Health 4(3)- 2020. MADOHC.MS.ID.000187. DOI: 10.32474/MADOHC.2020.04.000187. 


\section{Fabrication of metal framework}

a) A wax pattern for anterior metal ceramic bridge was fabricated using the template and cut back was done (Figure 7). b) Major connector and minor connectors were designed, and casting was done.

c) The metal framework was tried in the patient's mouth for fit and aesthetics.
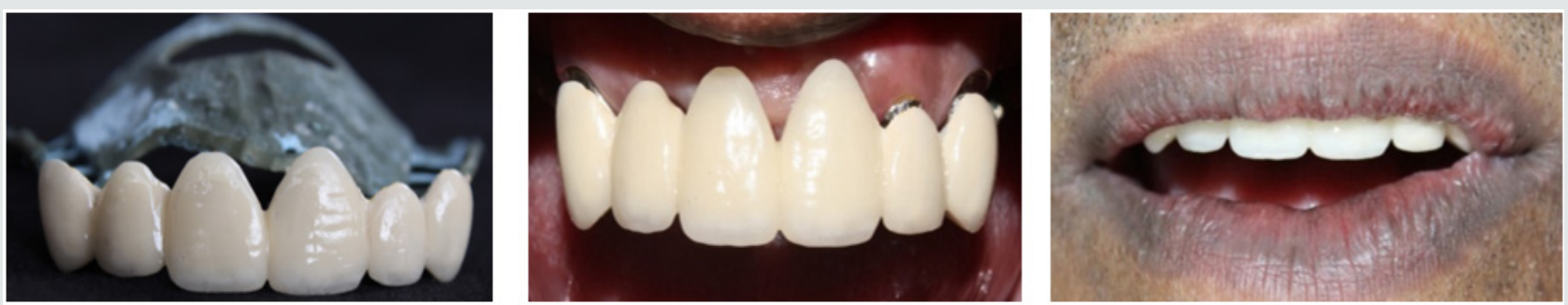

Figure 7: Tryin of the upper framework after ceramic build up.

\section{Completion of the prosthesis}

a) Ceramic layering was done for both maxillary and mandibular anterior teeth. An aesthetic try in procedure was carried out (Figure 8a \& 8b)

b) Definitive jaw relations were recorded, and the casts were mounted with the help of facebow transfer and centric relation record. c) Posterior teeth were arranged and try in was carried out to ensure balanced occlusion in the mouth.

d) Acrylization of the posterior teeth was carried out taking precautions not to damage the completed ceramic crowns.

e) The acrylised prosthesis was trimmed, polished and inserted in the mouth (Figure 9). Checked for occlusal contacts in centric and eccentric movements.

f) Patient was kept on a standard recall regimen
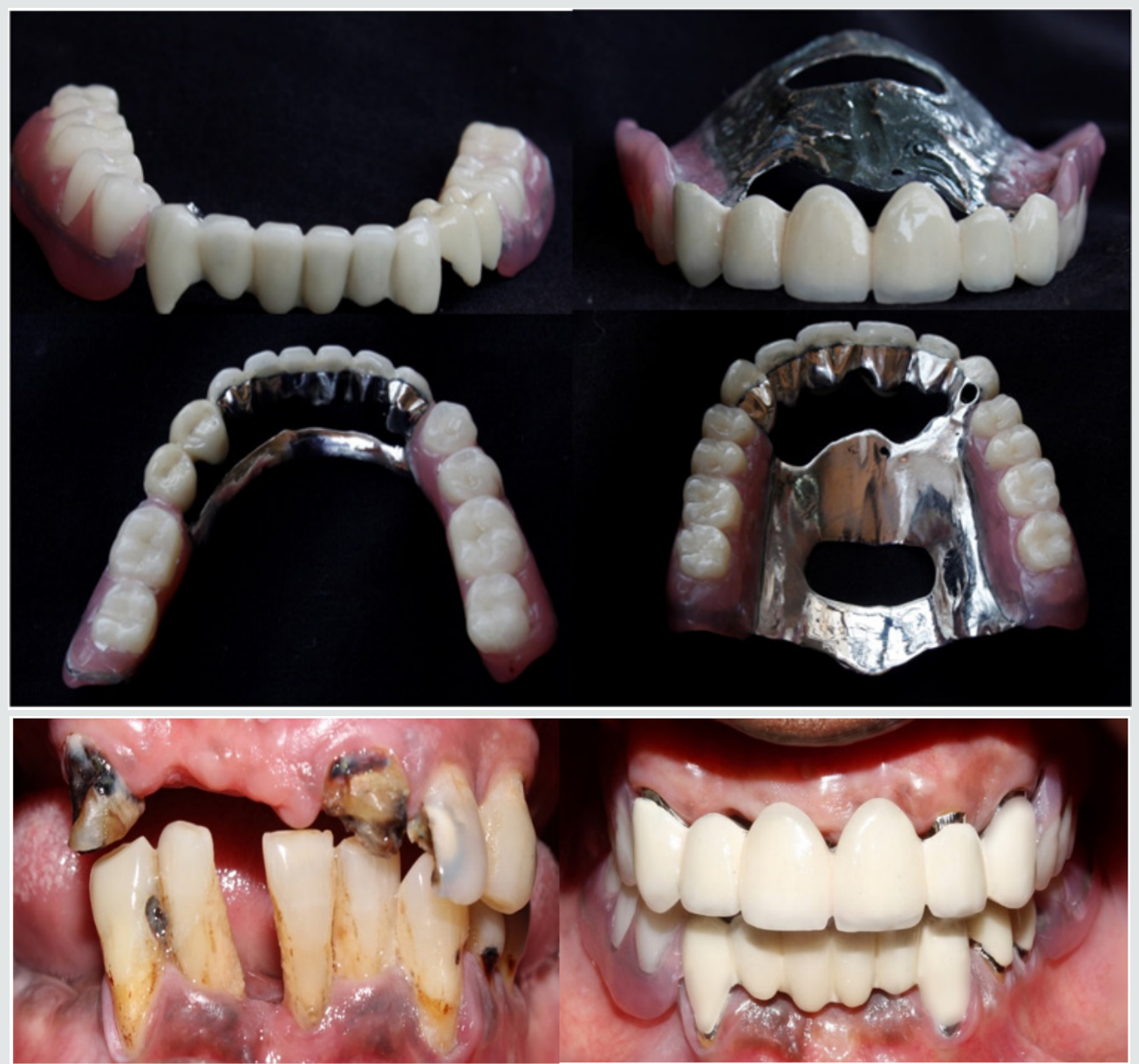

Figure 8: a) Completed upper and lower prosthesis; b) Preop and Postop intraoral photograph. 

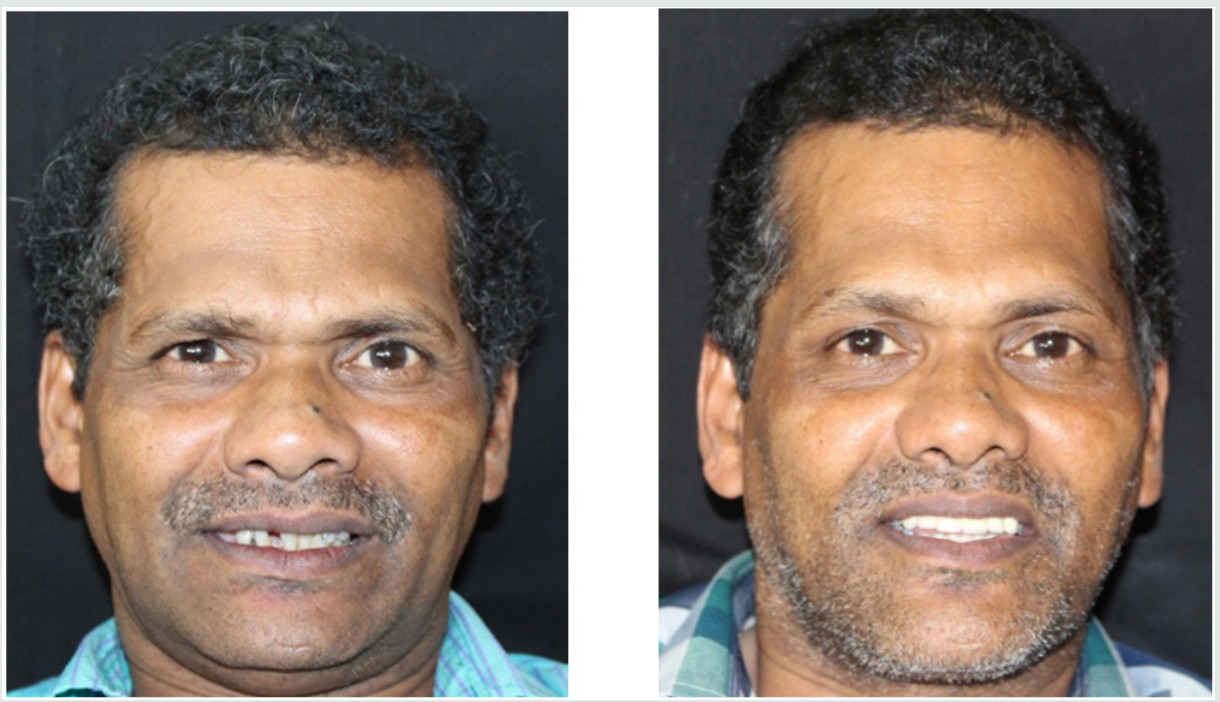

Figure 9: Preop Postop extra oral photograph.

\section{Discussion}

Preventive prosthodontics emphasizes the importance of any procedure that can delay or eliminate future Prosthodontic problems. Miller in 1958 stated that the maxilla and mandible were designed to house the teeth and not to support artificial denture [1]. In order to prevent alveolar ridge resorption and to maintain the ridge height the tooth was retained and dentures were constructed over it, hence the denture had good support During 1960s the concept of telescopic crown retained overdenture came into existence wherein the teeth were prepared and primary coping were given with parallel or tapered walls which will receive a secondary crown. The precisely made primary coping and secondary crown will have friction fit which will aid in retention of the prosthesis.

The weaker the tooth smaller will be the abutment preparation with more taper and the primary coping. While longer will be the primary coping with parallel walls in periodontally sound tooth. The longer and less tapered walls will provide better retention $[1,2]$. Telescopic crown retained removable dentures are indicated when there is presence of one third or less complement of alveolar bone, with unfavorable crown root ratio, loss of attached gingiva, remaining teeth poorly situated/tilted and with presence of adequate vertical dimension.

The advantage of this prosthesis includes, retention of natural teeth, maintaining proprioception, distribution of occlusal force to the alveolar bone equally and reduced bone resorption. It provides good support to the prosthesis and aids in retention of the prosthesis. It also acts as a periodontal splint for the remaining compromised teeth [3]. However, tedious laboratory process, increased cost, bulkiness of the prosthesis, loss of retention in long run limits the use of this kind of prosthesis. The major disadvantage is it is impossible to reline this kind of prosthesis [4-8].

In the present patient, the metal ceramic crowns that were given for anterior teeth help in reducing the bulk of the conventional telescopic removable partial denture. Apart from the above, the main advantage of using hybrid prosthesis is that, whenever the prosthesis is subjected to horizontal occlusal forces, there is dislodgement of the denture from the primary coping on the abutment. This reduces the load transfer to the abutment thereby increasing its life expectancy. Pezzoli et al. [7] evaluated the biomechanics of load transfer in telescopic denture and found out that the occlusal load is distributed uniformly to the abutments and edentulous areas [9].

\section{Conclusion}

A patient was successfully rehabilitated using telescopic metal ceramic crown for the remaining anterior natural teeth to support and retain a posterior removable partial denture was discussed. However, successful long-term treatment outcome would be accompanied by a routine periodontal and prosthodontic maintenance procedures.

\section{References}

1. Juliana PA, Henking (1982) Overdentures: Brewer AA, Morrow RM (Eds.), Journal of Dentistry, Mosby, Elsevier, USA, pp. 190.

2. Breitman JB, Nakamura S, Freedman AL, Yalisove IL (2012) Telescopic retainers: an old or new solution? A second chance to have normal dental function. J Prosthodont 21(1): 79-83.

3. Bhat VS, Prasad KD, Malli P (2015) Periodontal prosthesis-review. NITTE 5(1): 97-102.

4. Weaver JD (1989) Telescopic copings in restorative dentistry. J Prosthet Dent 61(4): 429-433.

5. Langer A (1981) Tooth-supported telescope restorations. J Prosthet Dent 45(5): 515-520.

6. Hou GL, Tsai CC, Weisgold AS (1997) Periodontal and prosthetic therapy in severely advanced periodontitis by the use of the crown sleeve coping telescope denture. A longitudinal case report. Aust Dent J 42(3): 169174.

7. Pezzoli M, Rossetto M, Calderale PM (1986) Evaluation of load transmission by distal-extension removable partial dentures by using reflection photoelasticity. J Prosthet Dent 56(3): 329-337.

8. Goswami R, Mahajan P, Siwach A, Gupta A (2013) Telescopic overdenture: Perio-prostho concern for advanced periodontitis. Contemp Clin Dent 4(3): 402-405.

9. Ragini B, Chandrasekar A, Praveen M, Aarti S, Gautham, et al. (2013) Telescopic overdenture. Journal of Orofacial Research 3(1): 57-62. 
(C) This work is licensed under Creative

To Submit Your Article Click Here: Submit Article

DOI: $10.32474 /$ MADOHC.2020.04.000187

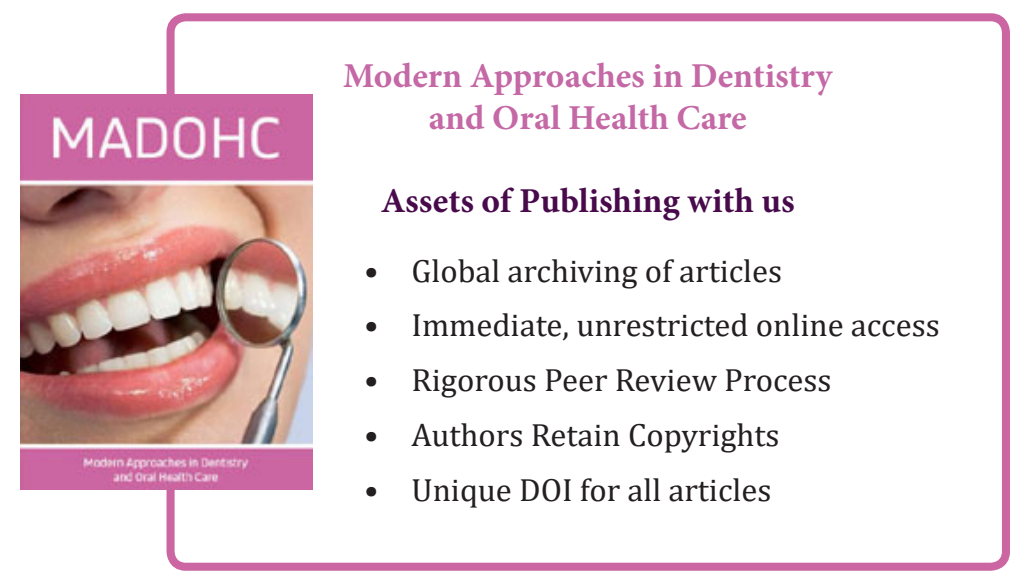

